\title{
Factors Responsible for Obesity Neuropathy among Bangladeshi Adults
}

\author{
K. C. Bhuyan* \\ Professor (Retired) of Statistics, Jahangirnagar University, Dhaka, Bangladesh. \\ *Corresponding Author: K. C. Bhuyan, Professor (Retired) of Statistics, Jahangirnagar University, \\ Dhaka, Bangladesh.
}

\begin{abstract}
The results presented here were found out in analysing the data collected from 960 adults of 18 years and above interviewed from both urban and rural areas of Bangladesh with an objective of identification of some socioeconomic variables responsible for the prevalence of obesity neuropathy. Among the adults $6.4 \%$ were the patients of obesity and neuropathy simultaneously. It was noted that urban people, males, Muslims, married persons, elderly people, illiterate people, physically inactive people, persons belonged to families of higher income and higher expenditure, adults involved in sedentary activity and habituated in taking restaurant food and hypertensive adults were more exposed to obesity neuropathy. The most responsible variable for this health hazard was smoking habit followed by physical inactivity, being male and housewife, can food user, and sedentary activity. These variables were identified by factor analysis.
\end{abstract}

Keywords: Obesity, Neuropathy, Diabetes, Hypertension, Duration of disease, Factor analysis, Factor loading.

\section{INTRODUCTION}

Obesity and overweight are the responsible factors for more than 30 chronic noncommunicable diseases, including diabetes, hypertension, cardiovascular diseases, high cholesterol, neuropathic pain and inflammation, migraine, musculoskelated system disorders such as low back pain, osteoarthrities, neck pain and many others poor health conditions [ 1,2 , 3,4 ]. Neuropathic pain that does not arise from musculoskelated damage is high in the high body mass index case [ 5]. The prevalence of obesity was increasing in many countries due to upward social mobility and the problem was shifting towards lower socioeconomic group of people $[6,7,8,9]$. The problem of obesity was also in increasing trend in developed countries $[6,7,8,9,10,11]$. It is a growing problem worldwide and is associated with a range of comorbidities, including cognitive dysfunction $[5,12]$. Obesity and high fat-feeding, lead to systematic inflammation and excess circulating free fatty acids. Central inflammation in obesity leads to negative outcomes on cognition. Migraine with aura, as obesity, is a risk factor for cardiovascular disease [5]. Again, obesity is associated with depression [13]. It is negatively correlated with quality life and physical activity [14 ].
In 2016, WHO reported that the overweight adults were 1.9 billion and obese adults were 650 million throughout the world [15]. Thus, World Health Organization considers this health hazard as an epidemic worldwide and it needs public health intervention to control those factors which are associated with obesity and hence with diabetes and its related health problem [ 16].

It had been observed in some studies, both in home and abroad, that behavioural factors, like dietary habit, physical inactivity, sedentary activity were the responsible factors for obesity and diabetes except the clinical and bi-clinical conditions $[17,18,19,20]$. Beside these, some other socioeconomic variables and clinical factors were also associated with obesity, and neurological problem [20 - 31].

Keeping the above neuropathic problem originated from obesity in mind, the objective of this study was planned to identify some socioeconomic characteristics responsible for obesity and neuropathy simultaneously.

\section{Methodology}

For the present study, it was decided to cover a quota of $70 \%$ diabetic adults by convenient sampling plan so that sufficient number of obese and neuropathic patients would be included in 
the sample [32]. The investigators who were doctors and nurses were instructed to collect data from and nearby their working places. But due to some social and physical constraints data were recorded from 960 adults covering $66.9 \%$ diabetic patients instead of $70 \%$. The remaining $33.1 \%$ were normal subjects. The sample respondents were of ages 18 years and above and they were interviewed from both urban and rural localities during academic session 2017 18. For data collection a pre-designed and pretested questionnaire had been utilized. Maximum questions in the questionnaire were related to different socioeconomic variables and lifestyle of the respondents including their existing medical condition and treatment status. Except personal socioeconomic information, data on monthly family income and monthly family expenditure were also recorded. The value of each of the variable was noted in nominal scale. The data of weight ( in $\mathrm{kg}$ ) divided by Height ( in metre ${ }^{2}$ ) was used to measure the value of body mass index (BMI) to identify obese adults( if BMI $\geq 27.5$; underweight, if $\mathrm{BMI}<18.5$; normal, if 18.5 $\leq \mathrm{BMI}<23.0$; overweight, if $23.0<\mathrm{BMI}<27.5$ ) [33,34 ].They were also divided into 4 groups according to their blood pressure (B.P) level ( $\mathrm{mmHg}$ ). The 4 groups were identified as optimal ( BP < 120/80), normal (BP <130/85), high normal ( $\mathrm{BP}<140 / 90)$ and hypertensive ( $\mathrm{BP} \geq 140 / 90)[35]$

According to the objective of the study, association of each of the socioeconomic characteristics with prevalence of obesity neuropathy was examined. Significant association was decided if probability of any Chi-square test statistic used for observing association $\leq 0.05$. Irrespective of significant or insignificant association, the odds ratio [O.R ] in favour of a higher group ( in percentage) of obese and neuropathic adults along with standard error of O.R. was calculated. Finally, factor analysis was done to identify responsible variables for obese and neuropathic adults. The responsible variables were identified depending on the higher absolute magnitude of factor loading [ 36,37 ]. All the statistical calculation was done using SPSS Version 25.

\section{RESULT}

The sample containeda total of 960 adults and $29.3 \%$ of them were obese [Table 1]. Among them $21.7 \%$ were the patients of obesity and neuropathy simultaneously as against $6.4 \%$ adults of this category in the sample. Majority $(43.9 \%)$ of the respondents were overweight but none of them was the patient of this health hazard.

Table1. Distribution of adults according to their level of obesity and prevalence of neuropathy

\begin{tabular}{|c|c|c|c|c|c|}
\hline \multirow[t]{3}{*}{ Levelof Obesity } & \multicolumn{3}{|c|}{ Prevalence of neuropathy } & \multicolumn{2}{|c|}{ Total } \\
\hline & \multicolumn{2}{|c|}{ Yes } & No & & \\
\hline & $\mathrm{n}$ & $\%$ & $\%$ & & \\
\hline Under-weight & 0 & 0.0 & 29100.0 & 29 & 3.0 \\
\hline Normal & 0 & 0.0 & 229100.0 & 229 & 23.9 \\
\hline Overweight & 0 & 0.0 & 421100.0 & 421 & 43.9 \\
\hline Obese & & 21.7 & $\begin{array}{ll}260 & 78.3 \\
\end{array}$ & 281 & 29.3 \\
\hline Total & 61 & 6.4 & $\begin{array}{ll}899 & 93.6\end{array}$ & $\overline{96}$ & \\
\hline
\end{tabular}

Similar was the case for adults of other two categories. However, level of obesity and prevalence of neuropathy was significantly associated $\left[\chi^{2}=157.400, \mathrm{p}\right.$-value $\left.=0.000\right]$.

The percentage of urban adults was 56.5 and prevalence of obesity neuropathy was noted among $7.7 \%$ of them. The corresponding percentage among rural adults was 4.5 . There was significant difference in the prevalence rates between urban and rural adults [Table 2, $\chi^{2}$ $=4.070, \mathrm{p}$-value $=0.042 \mathrm{]}$. Prevalence rate was 1.76 times more in urban adults than in rural adults [O.R.=1.76,S.E. $\{\ln ($ O.R. $)\}=0.285]$.

More Muslim (82.6\%) people were affected by $(6.7 \%)$ the prevalence of the disease compared to their non-Muslim counterpart (4.8\%). Muslim adults were $42 \%$ more exposed to this health problem, though religion was not associated with prevalence of obesity neuropathy $\left[\chi^{2}=0.831, \mathrm{p}\right.$ value $=0.362 ;$ O.R. $=1.42, \mathrm{~S} . \mathrm{E}\{\ln ($ O.R. $)\}=0.389]$. The percentage of female respondents was 44.8 and $8.8 \%$ of them were suffering from these diseases. The corresponding percentage for male was 4.3. The chance of prevalence in female was 2.14 times as it was in males. The proportions of prevalence in males and females were significantly different $\left[\chi^{2}=8.070, \mathrm{p}\right.$-value $=0.004$; O.R.= 2.14, S.E. $\{\ln ($ O.R. $)\}=0.273]$.

Married ( $69.8 \%)$ and Single $(30.2 \%)$ adults were not significantly different in respect of simultaneous prevalence rate of the diseases, 
Factors Responsible for Obesity Neuropathy among Bangladeshi Adults

Table2. Distribution of adults according to prevalence of obesity neuropathy and socioeconomic characteristics

\begin{tabular}{|c|c|c|c|c|c|c|}
\hline \multirow[t]{3}{*}{ Socioeconomic characteristics } & \multicolumn{4}{|c|}{ Prevalence of obesity neuropathy } & \multirow{2}{*}{\multicolumn{2}{|c|}{ Total }} \\
\hline & \multicolumn{2}{|c|}{ Yes } & \multicolumn{2}{|c|}{ No } & & \\
\hline & $\mathrm{n}$ & $\%$ & $\mathrm{n}$ & $\%$ & $\mathrm{n}$ & $\%$ \\
\hline \multicolumn{7}{|l|}{ Residence } \\
\hline Rural & 19 & 4.5 & 399 & 95.5 & 418 & 43.5 \\
\hline Urban & 42 & 7.7 & 500 & 92.3 & 542 & 56.5 \\
\hline Total & 61 & 6.4 & 899 & 93.6 & 960 & 100.0 \\
\hline \multicolumn{7}{|l|}{ Gender } \\
\hline Male & 23 & 4.3 & 507 & 95.7 & 530 & 55.2 \\
\hline Female & 38 & 8.8 & 392 & 91.2 & 430 & 44.8 \\
\hline \multicolumn{7}{|l|}{ Religion } \\
\hline Muslim & 53 & 6.7 & 740 & 93.3 & 793 & 82.6 \\
\hline Non-Muslim & 8 & 4.8 & 159 & 95.2 & 167 & 17.4 \\
\hline \multicolumn{7}{|l|}{ Marital status } \\
\hline Currently married & 47 & 7.0 & 623 & 93.0 & 670 & 69.8 \\
\hline Currently single & 14 & 4.8 & 276 & 95.2 & 290 & 30.2 \\
\hline \multicolumn{7}{|l|}{ Age ( in years) } \\
\hline$<20$ & 1 & 3.6 & 27 & 96.4 & 28 & 2.9 \\
\hline $20-30$ & 6 & 3.7 & 156 & 96.3 & 162 & 16.9 \\
\hline $30-40$ & 16 & 6.4 & 234 & 93.6 & 250 & 26.0 \\
\hline $40-50$ & 16 & 6.1 & 248 & 93.9 & 264 & 27.5 \\
\hline $50^{+}$ & 22 & 8.6 & 234 & 91.4 & 256 & 26.7 \\
\hline \multicolumn{7}{|l|}{ Education } \\
\hline Illiterate & 7 & 13.0 & 47 & 87.0 & 54 & 5.6 \\
\hline Primary & 8 & 7.0 & 107 & 93.0 & 115 & 12.0 \\
\hline Secondary & 21 & 9.2 & 208 & 90.8 & 229 & 23.9 \\
\hline Higher & 25 & 4.4 & 537 & 95.6 & 562 & 58.5 \\
\hline \multicolumn{7}{|l|}{ Occupation } \\
\hline Agriculture and unskilled labor & 15 & 5.9 & 240 & 94.1 & 255 & 26.6 \\
\hline Business and skilled labor & 7 & 4.3 & 154 & 95.7 & 161 & 16.8 \\
\hline Service & 8 & 3.8 & 205 & 96.2 & 213 & 22.2 \\
\hline Housewives, students and unemployed & 31 & 9.4 & 300 & 90.6 & 331 & 34.5 \\
\hline \multicolumn{7}{|l|}{ Income ( in 000 taka) } \\
\hline$<40$ & 24 & 7.7 & 287 & 92.3 & 311 & 32.4 \\
\hline $40-60$ & 7 & 3.7 & 182 & 96.3 & 189 & 19.7 \\
\hline $60-80$ & 7 & 3.7 & 181 & 96.3 & 188 & 19.6 \\
\hline $80-100$ & 12 & 7.5 & 148 & 92.5 & 160 & 16.7 \\
\hline $100^{+}$ & 11 & 9.8 & 101 & 90.2 & 112 & 11.7 \\
\hline \multicolumn{7}{|l|}{ Smoking habit } \\
\hline Yes & 21 & 5.6 & 35 & 94.4 & 373 & 38.9 \\
\hline No & 40 & 6.8 & 547 & 93.2 & 587 & 61.1 \\
\hline
\end{tabular}

Table2.Continued

\begin{tabular}{|c|c|c|c|c|c|c|}
\hline \multirow[t]{3}{*}{ Socioeconomic characteristics } & \multicolumn{4}{|c|}{ Prevalence of obesity neuropathy } & \multirow{2}{*}{\multicolumn{2}{|c|}{ Total }} \\
\hline & \multicolumn{2}{|c|}{ Yes } & \multicolumn{2}{|c|}{ No } & & \\
\hline & $\mathrm{N}$ & $\%$ & $\mathrm{n}$ & $\%$ & $\mathrm{n}$ & $\%$ \\
\hline \multicolumn{7}{|l|}{ Family expenditure ( in 000 taka) } \\
\hline$<30$ & 9 & 7.8 & 107 & 92.2 & 116 & 12.1 \\
\hline $30-50$ & 18 & 6.1 & 177 & 93.9 & 295 & 30.7 \\
\hline $50-70$ & 8 & 3.8 & 200 & 96.2 & 208 & 21.7 \\
\hline $70-90$ & 14 & 7.9 & 163 & 92.1 & 177 & 18.4 \\
\hline $90^{+}$ & 12 & 7.3 & 152 & 92.7 & 164 & 17.1 \\
\hline \multicolumn{7}{|l|}{ Taking restaurant food } \\
\hline Yes & 43 & 8.7 & 450 & 91.3 & 493 & 51.4 \\
\hline No & 18 & 3.9 & 449 & 96.1 & 467 & 48.6 \\
\hline \multicolumn{7}{|l|}{ Use of can food } \\
\hline Yes & 37 & 6.3 & 547 & 93.7 & 584 & 60.8 \\
\hline No & 24 & 6.4 & 352 & 93.6 & 376 & 39.2 \\
\hline
\end{tabular}




\begin{tabular}{|l|c|c|c|c|c|c|}
\hline Physical work & & & & & \\
\hline Yes & 18 & 5.1 & 333 & 94.9 & 351 & 36.6 \\
\hline No & 43 & 7.1 & 566 & 92.9 & 609 & 63.4 \\
\hline Utilization of time & & & & & & \\
\hline Read and use mobile phone & 2 & 1.4 & 137 & 98.6 & 139 & 14.5 \\
\hline Play and use mobile phone & 8 & 3.3 & 233 & 96.7 & 241 & 25.1 \\
\hline Do household work and watch T.V. & 22 & 8.9 & 225 & 91.1 & 247 & 25.7 \\
\hline $\begin{array}{l}\text { Read paper and use mobile phone after } \\
\text { office work }\end{array}$ & 11 & 4.4 & 238 & 95.6 & 249 & 25.9 \\
\hline $\begin{array}{l}\text { Watch T.V. and use mobile phone after } \\
\text { office work }\end{array}$ & 18 & 21.4 & 66 & 78.6 & 84 & 8.8 \\
\hline Prevalence of hypertension & & & & & & \\
\hline Optimal & 14 & 3.2 & 422 & 96.8 & 436 & 45.4 \\
\hline Normal & 26 & 6.9 & 353 & 93.1 & 379 & 39.5 \\
\hline High normal & 5 & 5.6 & 85 & 94.4 & 90 & 9.4 \\
\hline Hypertensive & 16 & 29.1 & 39 & 70.9 & 55 & 5.7 \\
\hline Prevalence of diabetes & & & & & & \\
\hline Yes & 22 & 3.4 & 620 & 96.6 & 642 & 66.9 \\
\hline No & 39 & 12.3 & 279 & 87.7 & 318 & 33.1 \\
\hline Duration of disease (in years ) & & & & & \\
\hline 0 & 20 & 2.5 & 788 & 97.5 & 808 & 84.2 \\
\hline$<1$ & 5 & 17.9 & 23 & 82.1 & 28 & 2.9 \\
\hline $1-3$ & 7 & 21.9 & 25 & 78.1 & 32 & 3.3 \\
\hline $3-5$ & 13 & 43.3 & 17 & 56.7 & 30 & 3.1 \\
\hline $5+$ & 6.4 & 899 & 93.6 & 960 & 100.0 \\
\hline Total & & & & & & \\
\hline
\end{tabular}

though married persons were $49 \%$ more exposed to this health hazard $\left[\chi^{2}=1.627, \mathrm{p}-\right.$ value $=0.202 ;$ O.R. $=1.49$, S.E. $\{\ln ($ O.R. $)\}=0.313$ ]. There was an insignificant increase in prevalence rates with the increase in ages. Maximum prevalence rate was observed in adults of ages 50 years and above. This group was $60 \%$ more exposed to this health problem and they were $26.7 \%$ in the sample. The rate of prevalence of obesity neuropathy was not significantly increased with the increase in ages [ $\chi^{2}=4.474, \mathrm{p}-$ value $=0.346 ;$ O.R $=$ 1.60,S.E. $\{\ln ($ O.R.) $\}=0.277]$. The percentage of illiterate people was only 5.6 , but $13.0 \%$ of them were affected by these diseases. The chance of prevalence was 1.34 times more in illiterate adults as it was in educated people [O.R. $=2.34$, S.E. $\{\ln (\mathrm{O} . \mathrm{R})\}=0.429]$. The decreasing trend in the rate of prevalence of obesity neuropathy was noted with the increase in level of education [ $\chi^{2}=10.516, \mathrm{p}$-value $\left.=0.015\right]$. Housewives, students and unemployed people were higher $(34.5 \%)$ in percentage in the sample and $9.4 \%$ of them were suffering from these two health problem simultaneously. The chance of prevalence of the problem among them was 2.06 times more as it was in other professional groups [ O.R.=2.06, S.E. $\{\ln ($ O.R $)\}=0.266$ ]. Significant differences in rates of prevalence in adults of different occupational patterns were observed $\left[\chi^{2}=8.646, \mathrm{p}-\right.$ value $=0.034$ ]. Again, it was noted that $63.4 \%$ respondents were not doing any physical labour and $7.1 \%$ of them were suffering from these diseases. The chance of prevalence in these group of respondents was 1.41 times more as it was in adults doing physical work. But there was insignificant differences in the proportions of prevalence between these two groups [ $\chi^{2}$ $=1.398, \quad \mathrm{p}$-value $=0.237 ;$ O.R. $=1.41$, S.E. $\{\ln ($ O.R. $)\}=0.289]$.

Family income of $28.3 \%$ adults was Tk.80,000.00 and above and obesity neuropathy was prevailed among $8.5 \%$ of them. They were $58 \%$ more exposed to this health hazard [ O.R. $=1.58$, S.E. $\{\ln ($ O.R. $)\}=0.274$ ]. However, significant differences in the rates of prevalence were not observed for adults belonged to families of different income levels $\left[\chi^{2}\right.$ $=8.005, \mathrm{p}$-value $=0.091]$. Similar was the case for respondents belonged to families of different levels of expenditure $\left[\chi^{2}=3.69, \mathrm{p}\right.$-value $=$ 0.464 ]. But adults belonged to families spending Tk.70,000.00 and above were $38 \%$ more exposed to this health hazard [ O.R.=1.38, S,E. $\{\ln ($ O.R. $)\}=0.268]$. Again, the chance of prevalence was 1.28 times for adults belonged to families spending lowest amount of money as family expenditure [ O.R.= 1.28 ]. 
The percentage of adults habituated in taking restaurant food was 51.4. The prevalence of obesity neuropathy was observed among $8.7 \%$ of them. The chance for this group of adults was 2.38 times as it was in other group of adults[ O.R. $=2.38$, S.R. $\{\ln ($ O.R. $)\}=0.289]$. Habit of taking restaurant food was significantly associated with the prevalence of obesity neuropathy $\left[\chi^{2}=9.550, \mathrm{p}-\right.$ value $\left.=0.002\right]$. Insignificant association between habit of taking can food [ $\chi^{2}=0.001, \mathrm{p}$-value $\left.=0.977\right]$ and prevalence of obesity neuropathy was noted, though $60.8 \%$ of the adults were used to take can food. Consumers and non-consumers of can food were similarly exposed to this health hazard [O.R.=1.01, S.E. $\{\ln ($ O.R. $)\}=0.271]$. Similar insignificant association between smoking habit and prevalence of obesity neuropathy was also noted $\left[\chi^{2}=0.54, \mathrm{p}\right.$-value $=0.214]$. From the sample, it was observed that $61.1 \%$ adults were non-smokers. But $6.8 \%$ of them were facing this health problem and they were $23 \%$ more exposed to this problem [ O.R.= 1.23, S.E. $\{\ln ($ R.R. $)\}=0.278 \quad$ ]. Among the sample respondents $8.8 \%$ passed their time by observing television and gossiping with others over mobile phone and $21.5 \%$ of them were the patients of obesity neuropathy. The prevalence of the disease in them was 5.28 times as it was in others[ O.R. $=5.28$, S.E. $\{\ln ($ O.R. $)\}=0.308]$. The prevalence of obesity neuropathy was significantly associated with utilization of time by the respondents $\left[\chi^{2}=45.726, \mathrm{p}-\right.$ value $=$ 0.000 ].

Out of 960 respondents $66.9 \%$ were diabetic patients. But only $3.4 \%$ of them were suffering from obesity neuropathy.

The chance of prevalence for this latter group of persons was 3.94 times as it was for diabetic adults [ O.R. $=3.94$, S.E. $\{\ln ($ O.R. $)\}=0.276]$ The prevalence of obesity neuropathy was significantly more among non-diabetic adults [ $=27.912, \mathrm{p}-$ value $=0.000] . \quad$ Significant association between level of hypertension and prevalence of obesity neuropathy was noted [ = $55.281, \mathrm{p}$-value $=0.000]$.The sample contained $5.7 \%$ hypertensive adults and $29.1 \%$ of them were suffering simultaneously from obesity and neuropathy. The corresponding figure for nondiabetic adult was $12.3 \%$. The prevalence for them was 7.84 times more as it was for other adults $\quad[$ O.R. $=7.84, \quad$ S.E. $\{\ln ($ O.R. $)\}=0.334]$. Duration of disease was significantly associated with prevalence of obesity neuropathy[ = 147.981 ,p-value $=0.000]$. Only $3.1 \%$ adults were suffering for 5 years or more from different diseases, but $43.3 \%$ were the patients of obesity and neuropathy simultaneously. The prevalence rate was 14.05 times for them as it was in others. [ O.R. $=14.05, \quad$ S.E. $\{\mathrm{ln}$ (O.R.) $\}=0.397$ ].

\section{FACTOR ANALYSIS}

According to the objective of the study, factor analysis was done using the variables residence. religion, gender, age, marital status, education, occupation, income, expenditure, utilization of time, habit of taking restaurant food and can food, physical activity, smoking habit, prevalence of diabetes, hypertension and duration of disease. Some of the variables were dropped from the analysis at final stage when communality of those variables were found less than 0.40 [38]. The results were shown in Table3.It was seen that the most responsible variable for the prevalence of obesity neuropathy was smoking habit followed by physical activity, occupation, gender, habit of taking can food and utilization of time.

Table3. Results of factor analysis

\begin{tabular}{|c|c|c|c|c|}
\hline \multirow{2}{*}{ Variable } & \multirow{2}{*}{ Communality } & \multicolumn{3}{|c|}{ Coefficient of } \\
\cline { 3 - 5 } & & Factor -1 & Factor-2 & Factor -3 \\
\hline Smoking habit & 0.743 & 0.854 & 0.018 & 0.111 \\
\hline Physical activity & 0.717 & -0.845 & -0.046 & 0.035 \\
\hline Occupation & 0.747 & 0.807 & 0.252 & 0.178 \\
\hline Gender & 0.645 & 0.767 & -0.091 & 0.220 \\
\hline Habit of taking can food & 0.582 & 0.573 & -0.484 & 0.129 \\
\hline Utilization of time & 0.625 & -0.363 & 0.198 & 0.674 \\
\hline Hypertension & 0.491 & -0.223 & 0.482 & 0.457 \\
\hline Income & 0.911 & 0.179 & 0.872 & -0.344 \\
\hline Expenditure & 0.932 & 0.134 & 0.901 & 0.320 \\
\hline Habit of taking restaurant food & 0.758 & 0.015 & -0.484 & -0.724 \\
\hline Age & 0.543 & 0.007 & -0.108 & 0.729 \\
\hline
\end{tabular}




\section{DISCUSSION}

Obesity is the cause of different types of noncommunicable diseases, viz. diabetes, hypertension, cardiovascular disease, depression $[1,2,8,10,13,31]$. Except these, clinical and subclinical aspects, specially, neurological problem of the type migraine, neuropathic pain, nerve damage, osteoarthritis, etc. are the problems of obese and diabetic patients $[1,3,5$, 12,28,41,42]. Some of the demographic characteristics are also responsible for the prevalence of obesity neuropathy $[1,7,8,9,11$, 13, 18, 19]. Accordingly, an attempt was made to identify the most responsible socioeconomic variable for this health hazard. To fulfil the objective, the analysis was done using the collected data of 960 adults of ages 18 years and above from both urban and rural localities of Bangladesh. Out of 960 adults, $66.9 \%$ were diabetic and $3.4 \%$ of them were suffering from both obesity and neuropathy as against $6.4 \%$ obese neuropathic patients in the sample. The percentage of obese adults was 29.3 and $21.7 \%$ of them were also neuropathic. A big group of adults were obese and diabetic and these two clinical aspects were the responsible factors for peripheral neuropathy. This phenomenon was noted earlier also [ 11]. This study also indicated that obesity originated neuropathic problem was dominant among Muslims, females, illiterate people, married people, elderly people, physically inactive people, hypertensive adults and people from urban area. In earlier study it was noted that female and lower educated people were in depression due to obesity $[13,31]$.

Due to higher economy lifestyle usually changes. People from higher economic conditions have the scope to be habituated with restaurant food and can food. These phenomena are the lifestyle factors. From this study it was noted that people having upward lifestyle were more exposed to the problem of obesity neuropathy. In earlier study also it was reported that quality life was the risk factor for obesity neuropathy [13]. However, the most responsible factor for the prevalence of obesity neuropathy was smoking habit. The other responsible variables were physical inactivity in terms of physical labour and occupation and sedentary activity.

\section{CONCLUSION}

The information contained in the paper were the analytical results of data collected from some rural and urban people of Bangladesh. The respondents were adults of ages 18 years and above. Number of investigated persons were 960.Out of them, $6.4 \%$ were suffering from obesity and neuropathy simultaneously. The percentages of urban people, Muslims, females, married persons and elderly people were 56.5, $82.6,44.8,69.8$, and 26.7 respectively. All these 5 groups were more exposed to the prevalence of obesity neuropathy. There were only $5.6 \%$ illiterate adults and for this group the chance of prevalence was 2.34 times as it was in other educated adults. The chance of prevalence was more than two times in physically inactive adults and more than 5 times for adults involved in sedentary activities. Upward quality lifestyle in respect of economy and food habit were the risk factors for the prevalence of obesity neuropathy. The chances of prevalence were 7.84 and 14.05 in hypertensive adults and in adults suffering for longer duration, respectively.

Factor analysis identified some responsible factors for the prevalence of obesity neuropathy. The most responsible one was smoking habit followed by physical inactivity, gender, habit of taking can food and sedentary activity.

Due to upward social mobility, obesity and diseases related to obesity cannot be avoided. But there should be some measures so that the rate of obesity in people can be reduced. Some of the suggested measures are

(i)To control the body weight by doing some physical work and developing the habit of walking whenever it is possible,

(ii)To avoid restaurant and can food, salty and fatty food and to develop the habit of taking home made food as per as possible,

(iii)To avoid smoking and taking drugs and drinks,

Government agencies providing health services in both urban and rural areas, social workers and private practitioners can encourage the people to follow the above suggestions.

\section{REFERENCES}

[1] Mokdad, A.H.; Ford,E.S.; Bowman,B.A.; Dietz, W.H.; Vinicor,F.; Bales,V.S. and Marks,J.S.( 2003): Prevalence of obesity , diabetes, and obesity-related health risk factors 2001, JAMA, 289,76 - 79.

[2] Barnes, S.A. (2011): The epidemic of obesity and diabetes: Trend and treatment, Tex Heart Inst.,38(2), $142-144$.

[3] Bigal,M.E.; Lipton, R.B.; Holland, P.R. and Goadsby, P.J. (2007): obesity, migraine, and chronic migraine : Possible mechanisms of interaction, Neurology, 68(21), 1851- 1861. 
[4] Miller, A.A.; Spencer, S.J. (2014): Obesity and neuroinflammation : a pathway to cognitive impairment, brain, behavior and immunity, 42, $10-21$.

[5] Houzumi, J.; Sumitani, M.; Matsubayashi, Y. Abe, H.; Oshima, Y.; Chikuda, H.; Takeshita, K.; and Yamada, Y.( 2016): Relationship between neuropathy pain and obesity, Pain Research Management, ArticleI.D. 2487924, https://doi.org/10.1155/2016/2487924

[6] Dhurandhar, N.V.(2001): Contribution of pathogene in human obesity. Drug News \& Perspectives, 7(5), 307- 313.

[7] Berg, C.; Rosengren, A.; Aives, N. et al (2005): Trendis in overweight and obesity from 1985 to 2002 in Goteberg, West Sweden, Inter. Jour. Obesity, 29(8), 916- 924.

[8] Skliros, E.A.; Merkoures, P.; Sotiropoulos, A. et al (2008): The relationship between body mass index and hypertension in elderly Greeks: The Nemea Primary Care Study, Jour Amer Geriatrics Society, 56(5), 954 - 955.

[9] Haslam, D.W. and James, W.P. (2005: Obesity, Lancet, 366, 1197 - 1209.

[10] John, E.H.; Jussara, M do, Carmo.; Alexander, A da Silva.; Zhen, W. and Michael, E.H. ( 2015): Obesity- Induced hypertension: Interaction of nuerohumoral and renal mechanisms, Circulation Research, 116, 991 -

[11] Theodore, A.K.(2010): Obesity-related hypertension: Epidemiology, Pathophysiology, and clinical management, Amer Jour Hypertension, 23(1), $1170 \quad-\quad 1178$. https://doi.org/10.1038/ajh.2010.172.

[12] Singleton, J.; Volckmann, E.; Graham, T. and Smith, A. (2014): Neurology associated with non-diabetic obesity, 82(10), (s36.006).

[13] Lassarre, A.M. ; Glauss,J. ; vandeleur,C.L.; Vidal, M.P.; Voucher, J.; Bastardot, F. Waeber,G. and Vollenweider,P. (2014): Depression with atypical features and increase obesity, body mass index, waist circumference and fat mass: A prospective population -based study, JAMA, Psychiatry, 71(8), 880- 888.

[14] Neuman, L.; Lerner, E.; Glazer, Y.; Bolotin,A.; Shefer, A and Buskila, D. (2008): A crosssectional study of the relationship between body mass index an clinical characteristics, tenderness measures, quality life, and physical functioning in fibromualgin patients, Clinical Rheumatology, 27(12), 1543 - 1547.

[15] WHO ( 2020): Fact Sheets/Detail/Obesity and overweight, March 2020.

[16] WHO ( 2007): The Challenge of obesity in the WHO European region and strategies for response; Edited by Branca, F. ; Nikogosian,H.; Lobstein, T.C. , Copenhagen.

[17] Weiss, R.; Dzria, J.; Burgert, T.S.et al ( 2014): Obesity and the metabolic syndrome in children and adolescents, N. Engl .J. Med.,350, 2362 2374.

[18] Dinsa, G.D.; Goryakin, Y. ; Fumagalli, E. and Suhrcke, M.( 2012): Obesity and socioeconomic status in developing countries: A systematic review, Obesity Reviews , 13(11), 1067-79,.Doi:10.1111/j.1467-789X.2012.010.x.

[19] Misra, A. and Khurana, L. ( 2008 ): Obesity and the metabolic syndrome in developinf countries, J Clin. Endocrinal Metab, 93, 51 - 58.

[20] Mansion, J.E. ; Willett, W.C. ;Colditz, G.A.; Hunter, D.J. ; Hankinsom ,S.E. ; Hennekens, C.H. and Speizer, F.E. ( 1995): Body weight and mortality among women, N Engl J Med, 333, 677- 685 .

[21] Redon, J., Cifkova, R.; Laurent, S. et al ( 2008): The metabolic syndrome in hypertension : European Society of hypertension position statement, Journal of Hypertension, 26(10), $1891-1900$.

[22] Fardus,J. and Bhuyan, K.C. (2016): Discriminating diabetic patients of some rural and urban areas of Bangladesh: A discriminant analysis approach, Euromediterrean Bio. Jour.11(9), 134 - 140.

[23] Biswas, T.; Garnett, P. Sarah and Rawal, B.Lal (2017): The prevalence of underweight, overweight, and obesity in Bangladesh: Data from a national survey, PLoS One, 12(5), e0177395.

[24] Appropriate Body Mass Index for Asian Population and its Implications for Policy and Intervention Strategies, WHO Expert Consultation, Public Health, Lancet 363, 2004.

[25] Jan, A.S. ; Yan, Li.; Azusa, H.; KEI, A.; Eamon, D. and O'Brien, E. : Blood pressure measurement anno 2016. Amer Jour Hypertens, 2017, 30(5), 453 - 463.https: //doi:org/10. 1093/ajh/hpw 148.

[26] Yotoka,T.(1983): Some criteria for variable selection in factor analysis, Behaviormetrika, 13,31 -45.

[27] Rusico, J. and Roche, B.( 2012): Determining the number of factors to retain in an exploratory factor analysis using comparison data of known factorial structure, Psychological Assessment, 24(2), 282 - 292, doi:10.1037/a 0025697

[28] Bhuyan,K.C. (2020): Socioeconomic variables responsible for exclusively diabetes among Bangladeshi adults, Acta Scientific Nutritional Health, 4(3), $01-06$. 
Factors Responsible for Obesity Neuropathy among Bangladeshi Adults

[29] Grundy, S.M.( 2004): Obesity, metabolic syndrome, and cardiovascular disease, Clin. Endocrinol Metab,89, 2595 - 2600.

[30] Felso, D.T.;Anderson, J.J.; Naimar, K.A.; Walker, A.M.; Meenan, R.F.(1998): Obesity and knee osteoarthirities: The Framingham Study, Ann. Int.Med., 109, 18 - 24.

[31] Bourne, R.; Mukhi, S.; Zhu, N.; Keresteci,M. (2007): Role of obesity on the risk for total hip or knee arthroplasty, Clin. Orthop.Relat.Res., $465,185-188$.

Citation: K. C. Bhuyan, "Factors Responsible for Obesity Neuropathy among Bangladeshi Adults", International Journal of Research Studies in Medical and Health Sciences. 2020; 5(9): 14-21.

Copyright: (c) $2020 \mathrm{~K}$. C. Bhuyan, This is an open-access article distributed under the terms of the Creative Commons Attribution License, which permits unrestricted use, distribution, and reproduction in any medium, provided the original author and source are credited. 